\title{
Unexpected plateauing of childhood obesity rates in developed countries
}

\author{
Martin Wabitsch ${ }^{1 *}$, Anja Moss ${ }^{1}$ and Katrin Kromeyer-Hauschild ${ }^{2}$
}

\begin{abstract}
Surveys performed in the past 10 to 15 years show a yet unexplained stabilization or decline in prevalence rates of childhood obesity in developed countries. The projected continuous increase in obesity prevalence throughout future decades seems not to occur at present. Apparently, saturation has been reached, which might be related to societal adjustments. Hence, we postulate a cumulative effect of public health programs for obesity prevention resulting, for example, in an increase in physical activity, and a decline in television viewing and in the consumption of sugar-sweetened soft drinks by children. Effective public health programs are urgently needed for developing countries, where obesity rates in children still continued to increase during the past decade.
\end{abstract}

Keywords: Obesity, Children and adolescents, Extreme obesity, Prevalence, Trend societal and environmental determinants

\section{Introduction}

One of the most striking changes in human biology, starting from around 1980, has been the worldwide dramatic increase in prevalence rates of overweight and obesity in children [1]. This impressive development has recently been followed by stabilization or even decline in prevalence rates [2-10]. This commentary highlights the published data on the recent stabilization in childhood obesity rates. These data and their interpretation can serve as a basis for future prevention programs.

\section{Past and recent trends in childhood obesity}

The body mass index (BMI), defined as weight $/(\text { height })^{2}$ is a surrogate parameter for body fat mass in adults and in children [11]. There are only a few datasets describing the cross-sectional development of BMI values in children over several decades before 1980. These data show a rather stable or slowly increasing prevalence of childhood obesity [12-15]. However, between 1980 and 2000, mean BMI values in children and the rates of childhood overweight and obesity increased dramatically in many countries [1]. This was paralleled by a steep increase in skinfold thickness, which is an anthropometric indicator

\footnotetext{
*Correspondence: martin.wabitsch@uniklinik-ulm.de

'Division of Pediatric Endocrinology and Diabetes, Interdisciplinary Obesity Unit, Department of Pediatrics and Adolescent Medicine, Ulm University, Eythstr. 24, D-89073 UIm, Germany

Full list of author information is available at the end of the article
}

of the amount of subcutaneous fat, and is widely used to assess body fat [16]. Skinfold thickness increased not only in overweight children, but also in normal and underweight children [17].

Along with the increase in obesity prevalence, the BMI distribution shifted in a skewed fashion, indicating that the heaviest children had become even heavier [18]. This matched the observation that the numbers of extremely obese children and adolescents (BMI $>99$ th percentile) increased to a greater degree than those of individuals in other obesity categories (BMI 95th to 96.9th and BMI 97th to 98.9 th percentile) $[19,20]$.

Starting at around the year 2000, childhood obesity rates apparently reached a plateaue or even declined in developed countries [2-10]. This was an unexpected finding, because, for example, in the USA, it has been suggested that the prevalence rate of obesity in children will reach $30 \%$ by 2030 [21]. Recent data from the National Health and Nutrition Examination Survey (NHANES) now show that the rapid increase in obesity prevalence rates seen in the 1980s and 1990s has not continued [5]. When sex differences were analyzed, the flattening was more marked for girls than for boys. Furthermore, there were age-related differences, with prevalence declining more in preschool children (aged 2 to 5 or 6 years) compared with primary school aged children (6 to 11 or 12 years) or adolescents (12 to 19 years) [6]. However, it should be noted 
that extreme obesity is still increasing, despite the declining rates for lower obesity categories $[19,20]$.

It is interesting that also in China, a developing country, stabilization of obesity rates has been observed. In the Jiangsu Province, no increase in the rate of overweight or obesity was seen in 12 to 14 -year-old students in both urban and rural areas [6]. We have summarized all published data known to us that report a leveling off or a decline in prevalence rates of childhood overweight and obesity in Table 1 . However, it should be noted that in all of the reported countries, the prevalence rates are still at a high level and still significantly higher than before 1980.

Possible causes and consequences of the observed trends in childhood obesity

Changes in BMI as a surrogate of body fat mass parallel changes in living conditions and energy intake over time. This has been shown in a study of children in Jena over a period of more than 100 years (Figure 1) [15]. This study used measurements based on 10 anthropological investigations carried out between 1880 and 2005/2006. It belongs to the longest running longitudinal studies of schoolchildren in a single community worldwide, and provides a unique dataset to analyze secular changes in the physical development of schoolchildren.

The dramatic increases in obesity prevalence rates and body fat after 1980 are related to changes in individual behaviors of children. Children nowadays have decreased physical activity, and increased screen time and consumption of energy-dense foods and snacks [1]. These behavioral changes are probably related to social and environmental changes that affect the whole population [18].

In return, the recent decline in obesity prevalence rates in children in developed countries may be the result of a cumulative effect of programs designed to prevent childhood obesity [23-25]. After 1980, the recognition by healthcare professionals, schools, community organizations, industry, and governments of obesity as a health problem increased. Both at national level and at state and local level, programs focusing on reducing the consumption of energy-dense foods and television viewing, as well as increasing the daily physical activity have been developed to reduce environmental factors contributing to inappropriate weight gain [23-25]. Although it is possible that a biological plateau for obesity has been

Table 1 Compilation of published data on stabilization or decline in prevalence rates of overweight and obesity in children in different countries

\begin{tabular}{|c|c|c|c|c|}
\hline Author & Publication year & Country & Year & Age group, years \\
\hline Olds et al. & 2010 & Australia & 1985 to 2008 & 2 to 18 \\
\hline Shi et al. & 2005 & China-Jiangsu Province & 2002 to 2007 & 12 to 14 \\
\hline Ministry of Health & $2003 ; 2008$ & New Zealand & 2002 to $2006 / 7$ & 5 to 14 \\
\hline Lissner et al. & 2010 & Sweden & 1999 to 2005 & 10 to 11 \\
\hline Murer et al. & 2013 & Switzerland & 1999 to 2012 & 6 to 12 \\
\hline Aeberli et al. & 2009 & Switzerland & 2002 to 2007 & 6 to 13 \\
\hline de Wilde et al. & 2009 & The Hague, Netherlands & 1999 to 2007 & 3 to 16 \\
\hline NHS Information Centre (NCMP) & 2010 & England & 1995 to 2007 & 2 to 15 \\
\hline Ministère de la Santé & 2010 & France & 1999 to 2007 & 5 to 15 \\
\hline Salanave et al. & 2009 & France & 2000 to 2007 & 7 to 9 \\
\hline Péneau et al. & 2009 & France & 1996 to 2006 & 6 to 15 \\
\hline Lioret et al. & 2009 & France & 1999 to 2007 & 3 to 14 \\
\hline Ogden et al. (NHANES) & 2012 & USA & 1999 to 2010 & 2 to 19 \\
\hline Moss et al. & 2012 & Germany & 1992 to 2009 & 5 to 7 \\
\hline Blüher et al. & 2011 & Germany & 1999 to 2008 & 4 to 16 \\
\hline Schmidt Morgen et al. & 2013 & Denmark & 1998 to 2011 & 3 mo to 16 yrs \\
\hline Mitchell et al. & 2007 & Scotland & 1997 to 2004 & 5,66 \\
\hline Tambalis et al. & 2010 & Greece & 1997 to 2007 & 8 to 9 \\
\hline Schnohr et al. & 2005 & Greenland & 1980 to 2004 & 6 to 7 \\
\hline CDC & 2013 & Anchorage, Alaska & $2003 / 4$ to $2010 / 11$ & 5 to 12 \\
\hline Popkin et al. & 2006 & Russia & 1995 to 2004 & 10 to 17,9 \\
\hline
\end{tabular}

Abbreviations: CDC, Centers for Disease Control and Prevention; NHANES, National Health and Nutrition Examination Survey; NHS, National Health Service; NCMP, National Child Measurement Programme. 

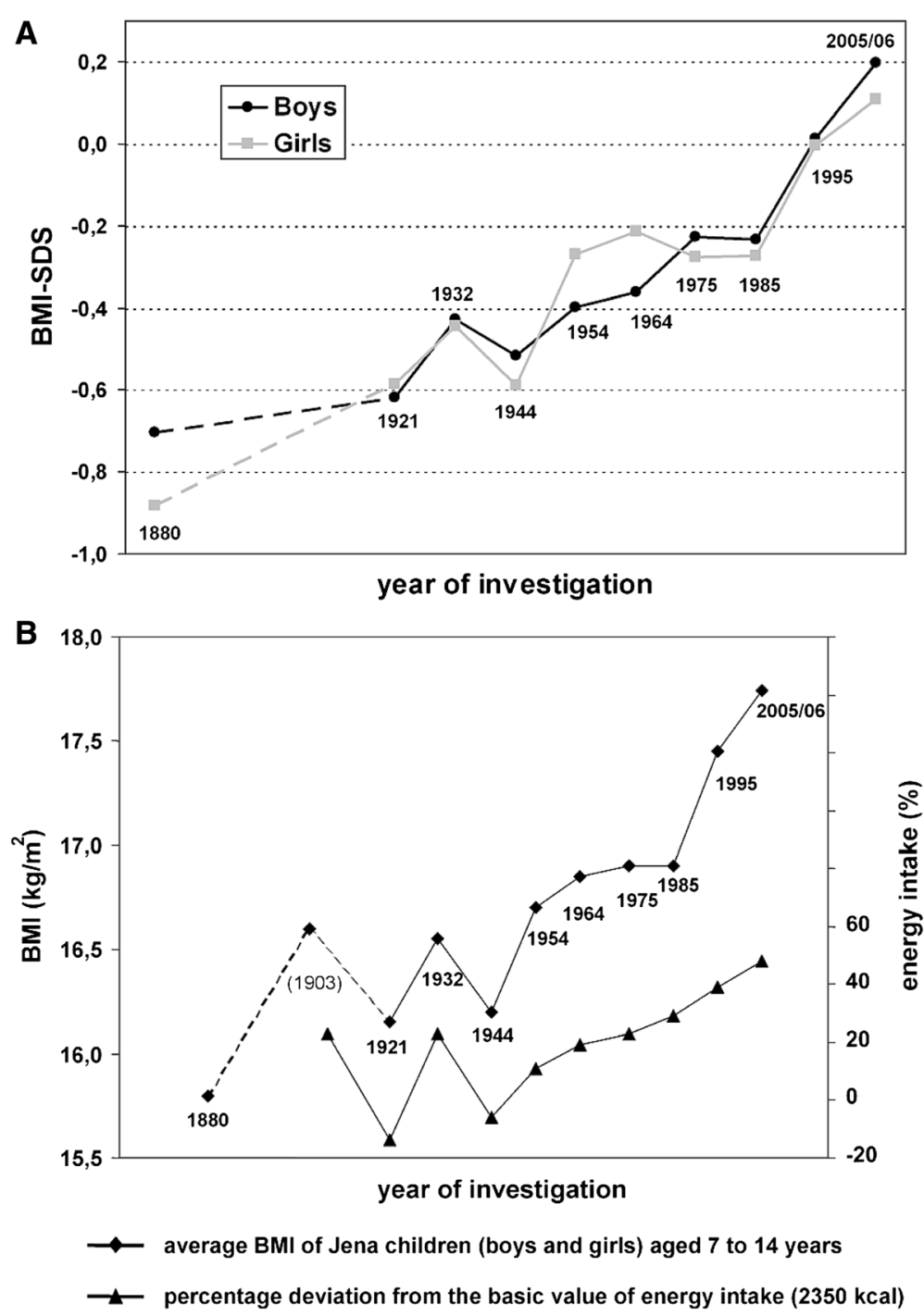

Figure 1 Changes in BMI parallel changes in living conditions and energy intake over time. (A) Development of body mass index standard deviation score (BMI SDS) of Jena schoolchildren (7 to 14 years of age) between 1880 and 2005. The children's average BMI SDS values increased slightly in the time period between 1880 and 2005/06, corresponding to a BMl increase of $1.8 \mathrm{~kg} / \mathrm{m}^{2}\left(0.14 \mathrm{~kg} / \mathrm{m}^{2}\right.$ per decade) in boys and of $2.1 \mathrm{~kg} / \mathrm{m}^{2}\left(0.17 \mathrm{~kg} / \mathrm{m}^{2}\right.$ per decade) in girls. This increase did not occur continuously. The marked increase in average BMI SDS between 1921 and 1932 indicates nutritional normalization following the famine due to World War I. This was followed by a downward shift in mean BMI between 1932 and 1944, reflecting a deterioration in living conditions during World War II. The marked increase in BMI SDS after 1985 was associated with a substantial increase in prevalence rate of obesity [22], and is a result of the dramatic changes in living conditions due to the German reunification. (B): Development and association of BMI and energy intake of Jena school children (7 to 14 years of age) between 1880 and 2005 (reproduced with permission from Zellner et al. [15]). The figure shows that BMI values as a surrogate of body fat mass paralleled the changes in energy intake over a time period of 100 years.

reached, there are several hints indicating that these initiated public health efforts have contributed to the leveling off of obesity rates.

A very recent study showed significant increases in daily physical activities and consumption of fruits and vegetables between 2001 and 2010 in a nationally representative cohort of students in grades 6 to 10. Television viewing and the consumption of sweets and sweetened beverages decreased during the same time period [26].
Another supporting example is the recently observed decline in the consumption of sugar-sweetened soft drinks by children, which parallels the decline in obesity prevalence rates $[27,28]$. These examples support the notion that in countries facing the childhood obesity epidemic over several years, the initiated public health programs have been able to stop the increasing obesity trends by influencing the lifestyle of children. If this can be confirmed in further analyses, such 
programs might even be improved in order to achieve a yet better success rate.

However, in contrast to these findings in developed countries, recent prevalence rates of overweight and obesity in children in developing low and middle income countries are still increasing at large [29]. This seems to be because the western lifestyle with easily available and low cost energy-dense food and increased motorization started to develop later in these countries, and had now become increasingly adopted [29]. These countries may be able to adapt public health programs from developed countries to their situation and launch them immediately in order to prevent further increases in childhood overweight and obesity rates, and possibly reach a plateau at a lower level than seen in developed countries.

\section{Conclusions}

The BMI of children is sensitive to living conditions and lifestyles, and the deep changes in children's living conditions and lifestyles in modern societies resulted in an extraordinary increase in childhood obesity rates from the 1980s. Unexpectedly, a plateau or even a decline in prevalence rates has been reported for several developed countries during the past 10 to 15 years. There are hints indicating that public health programs in these countries aiming at reducing obesity-promoting lifestyles might be responsible for the leveling off in obesity rates. However, it has to be recognized that despite the reported stabilization the prevalence rates of overweight and obesity in children, these rates remain at a high level and still represent a significant health issue.

\section{Competing interests}

The authors declare that they have no competing interests.

\section{Authors' contributions}

MW performed the literature research, wrote the first draft of the manuscript, and completed the final version. AM wrote sections of the manuscript, created figures and formatted the manuscript. KKH wrote sections of the manuscript and created figures. All authors read and approved the final manuscript.

\section{Acknowledgements}

This work was supported by grants of the German Federal Ministry for Education and Research (BMBF, project funding reference number 01Gl1120A), and is integrated in the Competence Network Obesity (CNO).

\section{Author details \\ 'Division of Pediatric Endocrinology and Diabetes, Interdisciplinary Obesity Unit, Department of Pediatrics and Adolescent Medicine, Ulm University, Eythstr. 24, D-89073 Ulm, Germany. ${ }^{2}$ Institute of Human Genetics, Jena University Hospital, Friedrich-Schiller-University Jena, Kollegiengasse 10, D-07740 Jena, Germany.}

Received: 10 January 2014 Accepted: 10 January 2014 Published: 31 Jan 2014

\section{References}

1. Lobstein T, Baur L, Uauy R: Obesity in children and young people: a crisis in public health. Obes Rev 2004, 5:4-104.
2. Matthiessen J, Velsing Groth M, Fagt S, Biltoft-Jensen A, Stockmarr A, Andersen JS, Trolle E: Prevalence and trends in overweight and obesity among children and adolescents in Denmark. Scand J Public Health 2008 , 36:153-160.

3. Popkin BM, Conde W, Hou N, Monteiro C: Is there a lag globally in overweight trends for children compared with adults? Obesity (Silver Spring) 2006, 14:1846-1853.

4. Bluher S, Meigen C, Gausche R, Keller E, Pfaffle R, Sabin M, Werther G, Odeh R, Kiess W: Age-specific stabilization in obesity prevalence in German children: a cross-sectional study from 1999 to 2008. Int J Pediatr Obes 2011, 6:e199-206.

5. Ogden CL, Carroll MD, Kit BK, Flegal KM: Prevalence of obesity and trends in body mass index among US children and adolescents, 1999-2010. JAMA 2012, 307:483-490.

6. Olds T, Maher C, Zumin S, Peneau S, Lioret S, Castetbon K, Bellisle, de Wilde J, Hohepa M, Maddison R, et al: Evidence that the prevalence of childhood overweight is plateauing: data from nine countries. Int $\mathrm{J}$ Pediatr Obes 2011, 6:342-360

7. Moss A, Klenk J, Simon K, Thaiss H, Reinehr T, Wabitsch M: Declining prevalence rates for overweight and obesity in German children starting school. Eur J Pediatr 2012, 171:289-299.

8. Mitchell RT, McDougall CM, Crum JE: Decreasing prevalence of obesity in primary schoolchildren. Arch Dis Child 2007, 92:153-154

9. Tambalis KD, Panagiotakos DB, Kavouras SA, Kallistratos AA, Moraiti IP, Douvis SJ, Toutouzas PK, Sidossis LS: Eleven-year prevalence trends of obesity in Greek children: first evidence that prevalence of obesity is leveling off. Obesity (Silver Spring) 2010, 18:161-166.

10. Schnohr C, Sorensen TI, Niclasen BV: Changes since 1980 in body mass index and the prevalence of overweight among inschooling children in Nuuk, Greenland. Int J Circumpolar Health 2005, 64:157-162.

11. Rolland-Cachera MF, Sempe M, Guilloud-Bataille M, Patois E, Pequignot-Guggenbuhl F, Fautrad V: Adiposity indices in children. Am J Clin Nutr 1982, 36:178-184.

12. Troiano RP, Flegal KM: Overweight children and adolescents: description, epidemiology, and demographics. Pediatrics 1998, 101:497-504.

13. Kuczmarski RJ, Flegal KM, Campbell SM, Johnson CL: Increasing prevalence of overweight among US adults. The National Health and Nutrition Examination Surveys, 1960 to 1991. JAMA 1994, 272:205-211.

14. Flegal KM, Carroll MD, Kuczmarski RJ, Johnson CL: Overweight and obesity in the United States: prevalence and trends, 1960-1994. Int J Obes Relat Metab Disord 1998, 22:39-47.

15. Zellner K, Ulbricht G, Kromeyer-Hauschild K: Long-term trends in body mass index of children in Jena, Eastern Germany. Econ Hum Biol 2007 5:426-434.

16. Olds TS: One million skinfolds: secular trends in the fatness of young people 1951-2004. Eur J Clin Nutr 2009, 63:934-946.

17. Nagel G, Wabitsch M, Galm C, Berg S, Brandstetter S, Fritz M, Klenk J, Peter R, Prokopchuk D, Steiner R, et al: Secular changes of anthropometric measures for the past 30 years in South-West Germany. Eur J Clin Nutr 2009, 63:1440-1443.

18. Flegal KM, Troiano RP: Changes in the distribution of body mass index of adults and children in the US population. Int J Obes Relat Metab Disord 2000, 24:807-818

19. Wang YC, Gortmaker SL, Taveras EM: Trends and racial/ethnic disparities in severe obesity among US children and adolescents, 1976-2006. Int J Pediatr Obes 2011, 6:12-20.

20. Skelton JA, Cook SR, Auinger P, Klein JD, Barlow SE: Prevalence and trends of severe obesity among US children and adolescents. Acad Pediatr 2009, 9:322-329.

21. Wang Y, Beydoun MA, Liang L, Caballero B, Kumanyika SK: Will all Americans become overweight or obese? Estimating the progression and cost of the US obesity epidemic. Obesity (Silver Spring) 2008, 16:2323-2330.

22. Kromeyer-Hauschild K, Zellner K: Trends in overweight and obesity and changes in the distribution of body mass index in schoolchildren of Jena, East Germany. Eur J Clin Nutr 2007, 61:404-411.

23. Bae SG, Kim JY, Kim KY, Park SW, Bae J, Lee WK: Changes in dietary behavior among adolescents and their association with government nutrition policies in Korea, 2005-2009. J Prev Med Public Health 2012, 45:47-59.

24. Fernandes MM: A national evaluation of the impact of state policies on competitive foods in schools. J Sch Health 2013, 83:249-255. 
25. Andreyeva T, Luedicke J, Tripp AS, Henderson KE: Effects of reduced juice allowances in food packages for the women, infants, and children program. Pediatrics 2013, 131:919-927.

26. lannotti RJ, Wang J: Trends in physical activity, sedentary behavior, diet, and BMI among US adolescents, 2001-2009. Pediatrics 2013, 132:606-614.

27. Jensen BW, Nichols $M$, Allender S, de Silva-Sanigorski A, Millar L, Kremer P, Lacy K, Swinburn B: Consumption patterns of sweet drinks in a population of Australian children and adolescents (2003-2008). BMC Public Health 2012, 12:771.

28. Kit BK, Fakhouri TH, Park S, Nielsen SJ, Ogden CL: Trends in sugar-sweetened beverage consumption among youth and adults in the United States: 1999-2010. Am J Clin Nutr 2013, 98:180-188.

29. de Onis M, Blossner M, Borghi E: Global prevalence and trends of overweight and obesity among preschool children. Am J Clin Nutr 2010, 92:1257-1264.

10.1186/1741-7015-12-17

Cite this article as: Wabitsch et al:: Unexpected plateauing of childhood obesity rates in developed countries. BMC Medicine 2014, 12:17

\section{Submit your next manuscript to BioMed Central and take full advantage of:}

- Convenient online submission

- Thorough peer review

- No space constraints or color figure charges

- Immediate publication on acceptance

- Inclusion in PubMed, CAS, Scopus and Google Scholar

- Research which is freely available for redistribution 